\title{
Endoscopic Findings and Their Association With Gender, Age and Duration of Symptoms in Patients With Dysphagia
}

\author{
Hafsa Rashid ${ }^{1}$, Khush Bakht ${ }^{2}$, Amna Arslan ${ }^{3}$, Amna Ahmad ${ }^{4}$ \\ 1. Gastroenterology and Hepatology, Pakistan Emirates Military Hospital, Rawalpindi, PAK 2. Internal Medicine, \\ Shalimar Medical College, Lahore, PAK 3. Internal Medicine, Fauji Foundation Hospital, Lahore, PAK 4. Diagnostic \\ Radiology, Shaikh Zayed Hospital, Lahore, PAK
}

Corresponding author: Hafsa Rashid, drhafsamalik88@gmail.com

\begin{abstract}
\section{Introduction}

Dysphagia is highly prevalent in patients with a history of recurrent acid peptic disease. Endoscopy is the mainstay of diagnostic workup of these patients to reach underlying cause and appropriate subsequent treatment. The objective of the study was to determine the frequency of various types of endoscopic findings in patients with dysphagia and the association of these findings with gender, age and duration of symptoms.
\end{abstract}

\section{Methods}

This cross-sectional study was carried out in the Department of Gastroenterology of a tertiary care hospital in Rawalpindi, Pakistan. A total of 137 patients who presented with a history of dysphagia for at least two weeks were enrolled in the study. Duration of symptoms was noted, and all patients underwent upper gastrointestinal endoscopy to find out the cause of dysphagia. Tissue biopsies were obtained, and further histopathological examination was performed to correlate the findings with symptoms of dysphagia.

\section{Results}

A total of 137 patients were enrolled for six months. The mean age of the patients was $56.9 \pm 17.44$ years, and the mean duration of symptoms was $15.96 \pm 12.31$ weeks. There were 65 (47.4\%) males and $72(52.6 \%)$ females in the study. Majority of them, 123 (89.8\%), presented with a short duration of symptoms that varied between 2-24 weeks and were mainly middle-aged (31-60 years) and old-aged (61-80 years). The most commonly observed endoscopic findings were esophageal stricture in 25 (18.2\%), achalasia cardia in 20 (14.6\%), esophageal mass in $12(8.8 \%$ ) and reflux esophagitis in 7 (5\%) patients. No association was seen between age, gender and duration of symptoms and findings on the endoscopy.

Review began 10/15/2020 Review ended 10/22/2020 Published 10/30/2020

\section{(c) Copyright 2020}

Rashid et al. This is an open access article distributed under the terms of the Creative Commons Attribution License CC-BY 4.0., which permits unrestricted use, distribution, and reproduction in any medium, provided the original author and source are credited.

\section{Conclusion}

Dysphagia is associated with many endoscopic findings that are not related to demographic variables and must be evaluated earlier to reduce further morbidity and mortality.

Categories: Internal Medicine, Gastroenterology

Keywords: dysphagia, endoscopic findings, duration of symptoms

\section{Introduction}

Dysphagia is the symptom that describes the difficulty in swallowing due to any cause [1]. Numerous established reasons for dysphagia have been reported, but the prevalence varies in different regions. Various studies have reported dysphagia to range between 6-9\% in other age groups. In patients above 50 years of age, dysphagia affects $16-22 \%$ of the population [2].

The most frequently performed procedure for initial diagnosis and evaluation of dysphagia of esophageal origin is upper gastrointestinal (GI) endoscopy [3]. It helps in the visualization of the entire esophagus directly and also aids in taking tissue for biopsy. It is essential to diagnose the cause of dysphagia early because it is linked with significant morbidity and mortality [4]. Upper GI endoscopy is a safe procedure and has a risk of complications of 1 per 1000 procedures approximately [3]. The most common complications seen are bleeding, infection, perforation and cardio-pulmonary issues $[1,5]$.

The findings on endoscopy in patients with dysphagia are well known. In one literature review, it was found that in patients who had dysphagia, upper GI endoscopy revealed that 32.5\% patients had normal findings, $25 \%$ had Schatzki's ring, 22.5\% had malignant esophageal stricture, $10 \%$ had reflux esophagitis, and $5 \%$ had 


\section{Cureus}

a benign stricture of esophagus [5-7]. In another study, it was found that $21 \%$ had a benign stricture of esophagus, and $14 \%$ of patients were diagnosed with achalasia [2].

Numerous studies have been carried out on the findings of endoscopy with dysphagia; however, the prevalence of these findings have not been well documented in local databases of Pakistan. Therefore, the current study aimed to determine the frequency of endoscopic findings in patients with dysphagia and the association of these findings with age, gender and duration of symptoms.

\section{Materials And Methods}

It was a cross-sectional study conducted at the Department of Gastroenterology and Hepatology, Pak Emirates Military Hospital, Rawalpindi, Pakistan for a period of six months from July 2018 to December 2018. A sample size of 137 was calculated using the Epi-Pen calculator based on the prevalence of dysphagia to be $9 \%$ in general population-based on previous studies (8). The patients were recruited using consecutive non-probability sampling. All patients presenting with dysphagia from age 18-80 years were included in the study. Patients with a previous history of upper gastrointestinal (GI) endoscopy and any past GI surgery were excluded from the study. The study was conducted following principles of ethical medical practice as laid down in the Declaration of Helsinki after obtaining its formal approval from the Ethical Committee of the same institution.

Patients fulfilling the inclusion criteria were recruited in the study after obtaining informed written consent. The patients were assessed with adequate history, thorough examination and investigations and findings were noted down on a pre-designed proforma. Endoscopy was performed by the same consultant gastroenterologist (HR), and biopsies were taken where required and were sent for histopathological analysis. The results of the analysis were recorded on the proforma and were subjected to statistical analysis. Radiography was advised in all cases to see radiological findings in patients with dysphagia.

The data were entered and analyzed through Statistical Package for Social Sciences (SPSS version 24.0, IBM Statistics, IL, USA). Quantitative data such as age and duration of symptoms were presented as mean and standard deviation. Qualitative data such as gender, age groups, duration of symptoms, physical findings, radiological findings, endoscopic findings and biopsy findings were calculated as frequencies and percentages. Chi-square test was used to compare qualitative data, whereas a student's t-test was used for quantitative variables. A p-value of $\leqslant 0.05$ was considered as statistically significant.

\section{Results}

A total of 137 patients were enrolled in this study. The mean age of the patients was $56.9 \pm 17.4$ years, and the mean duration of symptoms was $16.0 \pm 12.3$ weeks. There were 65 (47.4\%) males and 72 (52.6\%) females in the study. Distribution of patients in various age groups and duration of dysphagia is shown in Table 1. Findings of the patients on physical examination and their radiographic investigations are presented below (Table 2, 3).

\begin{tabular}{|c|c|c|}
\hline Study variables & Number of Patients $\quad[n(\%)]$ & p-Value (chi-square test) \\
\hline \multicolumn{3}{|l|}{ Gender } \\
\hline Male & $65(47.4 \%)$ & 0.45 \\
\hline Female & $72(52.6 \%)$ & \\
\hline \multicolumn{3}{|l|}{ Age groups (years) } \\
\hline Young age (18-30) & $18(13.1 \%)$ & \\
\hline Middle age (31-60) & $57(41.6 \%)$ & 0.073 \\
\hline Old age (61-80) & $62(45.3 \%)$ & \\
\hline \multicolumn{3}{|l|}{ Duration of dysphagia (weeks) } \\
\hline Short duration (2-24) & $123(89.8 \%)$ & 0.988 \\
\hline Long duration (25-48) & $13(9.5 \%)$ & \\
\hline Extremely long duration $(>48)$ & $1(0.7 \%)$ & \\
\hline
\end{tabular}

TABLE 1: Demographic variables of the study population 


\section{Cureus}

\begin{tabular}{|l|l}
\hline Physical findings & $\mathrm{n}(\%)$ \\
\hline Emaciated & $10(7.3 \%)$ \\
Hyperthyroid & $1(0.7 \%)$ \\
Hypothyroid & $2(1.5 \%)$ \\
Known case of celiac & $1(0.7 \%)$ \\
Known case of ILD & $1(0.7 \%)$ \\
Loss of weight & $39(28.5 \%)$ \\
Pallor & $72(52.6 \%)$ \\
Paralysis & $7(5.1 \%)$ \\
Parkinsonism & $2(1.5 \%)$ \\
Ptosis & $1(0.7 \%)$ \\
No findings & $1(0.7 \%)$
\end{tabular}

\section{TABLE 2: Physical examination findings of patients with dysphagia}

ILD- Interstitial lung disease

\begin{tabular}{|c|c|}
\hline Radiological findings & n (\%) \\
\hline Achalasia cardia & 19 (13.9\%) \\
\hline Lower esophageal narrowing & $1(0.7 \%)$ \\
\hline Dilated esophagus & $5(3.6 \%)$ \\
\hline Hiatus hernia & $1(0.7 \%)$ \\
\hline Stricture & $30(21.9 \%)$ \\
\hline Diverticulum & $4(2.9 \%)$ \\
\hline Ulcer & $2(1.5 \%)$ \\
\hline Stricture (malignant) & $1(0.7 \%)$ \\
\hline Nutcracker esophagus & $1(0.7 \%)$ \\
\hline No finding & $73(53 \%)$ \\
\hline
\end{tabular}

\section{TABLE 3: Radiological findings in patients with dysphagia}

Various endoscopic findings were seen in 57 (41.6\%) patients in the elderly (61-80 years) as described below. The most common findings in this age group were achalasia cardia in 10 (7.3\%), esophagitis in $8(5.8 \%)$ and esophageal masses in 7 (5.1\%). In middle age group (31-60 years), endoscopic findings were present in 50 (36.5\%) patients and the most common findings were esophageal stricture 14 (10.2\%), esophageal mass 5 (3.6\%) and achalasia in 5 (3.6\%). Among young age group (18-30 years), positive endoscopic findings were observed in 15 (11.0\%) patients and the most common findings were of achalasia cardia in $5(3.6 \%)$, corrosive stricture in 4 (2.9\%) and esophageal stricture in $3(2.2 \%)$. Despite variability in presentations at different age groups, there was no significant association found between age and endoscopic findings (Table 4).

Endoscopic Findings

Normal findings n (\%)

$15(10.9 \%)$ 


\section{Cureus}

\begin{tabular}{|c|c|}
\hline Esophageal web & $4(2.9 \%)$ \\
\hline Peptic stricture & $4(2.9 \%)$ \\
\hline Lax LES & $1(0.7 \%)$ \\
\hline Gastric mass & $2(1.5 \%)$ \\
\hline Reflux esophagitis & $7(5.1 \%)$ \\
\hline Esophageal growth & $1(0.7 \%)$ \\
\hline GEJ growth & $5(3.6 \%)$ \\
\hline Zenkar diverticulum & $1(0.7 \%)$ \\
\hline Multiple ulcers in esophagus & $1(0.7 \%)$ \\
\hline Growth hypopharynx & $3(2.2 \%)$ \\
\hline Esophageal mass & $12(8.8 \%)$ \\
\hline Esophageal candidiasis & $4(2.9 \%)$ \\
\hline Superficial ulcers in esophagus & $1(0.7 \%)$ \\
\hline Superficial ulcers in larynx and pharynx & $1(0.7 \%)$ \\
\hline Peptic stricture at $35 \mathrm{~cm}$ & $1(0.7 \%)$ \\
\hline Diffuse hypertrophy of stomach & $1(0.7 \%)$ \\
\hline Esophagitis & $1(0.7 \%)$ \\
\hline Globus hystericus & $1(0.7 \%)$ \\
\hline Cockscrew esophagus & $1(0.7 \%)$ \\
\hline Hiatus hernia and barrets esophagus & $2(1.5 \%)$ \\
\hline Foreign body & $1(0.7 \%)$ \\
\hline Achalasia cardia & $20(14.6 \%)$ \\
\hline Growth of larynx & $2(1.5 \%)$ \\
\hline Schatzki ring & $2(1.5 \%)$ \\
\hline Nodular mucosa of stomach & $1(0.7 \%)$ \\
\hline Growth of pharynx, larynx and esophagus & $1(0.7 \%)$ \\
\hline Nutcracker esophagus & $1(0.7 \%)$ \\
\hline Barrets esophagus Stricture at GEJ & $3(2.2 \%) 1(0.7 \%)$ \\
\hline Corrosive stricture & $4(2.9 \%)$ \\
\hline Pharyngeal mass & $1(0.7 \%)$ \\
\hline Esophageal mucosal bulge & $1(0.7 \%)$ \\
\hline Hiatus hernia with cameron lesion & $1(0.7 \%)$ \\
\hline Esophageal stricture & $25(18.2 \%)$ \\
\hline Esophageal diverticulum & $4(2.9 \%)$ \\
\hline
\end{tabular}

\section{TABLE 4: Findings of upper gastrointestinal endoscopy in patients with dysphagia}

GEJ- Gastroesophageal Junction

With regards to gender, 60 males and 62 females had positive findings on upper GI endoscopy (p-value > $0.05)$. The common results in males were esophageal stricture 14 (10.2\%), achalasia cardia in $10(7.3 \%)$, 


\section{Cureus}

esophageal mass in 5 (3.6\%) and gastro-oesophagal junctional (GEJ) growth in 4 (2.9\%). In females, the typical findings were esophageal stricture $11(8 \%)$, achalasia cardia 10 (7.3\%), esophageal mass 7 (5.1\%) and corrosive stricture in $4(2.9 \%)$. There was no statistically significant association between gender and the findings on endoscopy in patients who presented with dysphagia.

In patients who presented with short duration of dysphagia, i.e. from 2 to 24 weeks, the most common findings were esophageal stricture in $22(16.1 \%)$ patients, achalasia cardia in $19(13.9 \%)$, esophageal mass in 9 (6.6\%), reflux esophagitis in 7 (5.1\%), GEJ growth in 5 (3.6\%) and esophageal stricture, esophageal candidiasis, esophageal diverticulum and peptic stricture in 4 (2.9\%) each. Among patients who presented with long duration of dysphagia, i.e. from 25-48 weeks, common endoscopic findings were of esophageal stricture in $3(2.2 \%)$ and corrosive stricture in $2(1.5 \%)$ patients. No endoscopic finding was found in patients who presented with too long duration dysphagia, i.e. $>48$ weeks. No significant association was found between the duration of dysphagia and endoscopic findings as indicated by the $p$-value of $>0.05$. The results of tissue histopathological examination are presented below (Table 5).

\begin{tabular}{|l|l|}
\hline Biopsy findings & $\mathrm{n}(\%)$ \\
\hline Squamous cell carcinoma & $14(10.2 \%)$ \\
\hline Adenocarcinoma & $1(0.7 \%)$ \\
\hline Intestinal metaplasia & $1(0.7 \%)$ \\
\hline Benign stricture & $2(1.5 \%)$ \\
\hline Achalasia cardia & $6(4.4 \%)$ \\
\hline Zenkar diverticulum & $1(0.7 \%)$ \\
\hline Peptic stricture & $4(2.9 \%)$ \\
\hline Drug induced esophagitis & $1(0.7 \%)$ \\
\hline Esophageal candidiasis & $1(0.7 \%)$ \\
\hline Reflux esophagitis & $1(0.7 \%)$ \\
\hline Biopsy not done & $105(76.6 \%)$ \\
\hline
\end{tabular}

\section{TABLE 5: Findings of histopathological examination in dysphagia patients}

\section{Discussion}

Dysphagia is a frequent complaint of patients presenting in GI clinics [7-10]. The causes of dysphagia of esophageal origin that are identified commonly are benign and malignant strictures of esophagus, reflux esophagitis, Schatzki's ring, compression occurring externally from a malignancy, disorders of motility, scleroderma and achalasia [11-16]. In some population-based studies, the rates of prevalence of dysphagia have been reported to be $17-25 \%$ with a peak in symptoms at the age of $40-49$ years for both gender [17,18]. More commonly, it is seen in old age patients and in those who were hospitalized [19]. The modality of choice for making a diagnosis of dysphagia is upper gastrointestinal endoscopy and has a good safety profile too $[20,21]$.

The most common findings in the study on endoscopy in patients who presented with dysphagia were esophageal stricture in 25 (18.2\%), achalasia cardia in 20 (14.6\%), esophageal mass in 12 (8.8\%), reflux esophagitis in 7 (5.1\%), esophageal diverticulum in 4 (2.9\%), corrosive stricture in 4 (2.9\%), esophageal candidiasis in 4 (2.9\%), esophageal web in 4 (2.9\%) and peptic stricture in 4 (2.9\%).

Esophageal stricture was seen more in patients who were of middle age $(14,10.2 \%)$ followed by in old age patients above 60 years of age $(8,5.8 \%)$. It was more frequent in males $(14,10.2 \%)$ compared to females (11, $8.0 \%$ ) and was more common in patients who presented with short duration of dysphagia (2-24 weeks) as compared to patients who presented with long term (> 48 weeks) $(22,16.1 \%$ versus $3,2.2 \%)$. This implies that esophageal stricture is mainly found in middle-aged males with short duration of symptoms of dysphagia. In a study by Eslick et al. [5] it was found to be the second most common cause of dysphagia (22, $17.3 \%$ patients). The study revealed that it was more common in 30-50 years old patient with long duration of symptoms (>24 weeks). The findings of the study were similar to our study in terms of age of the patients. Both these studies revealed that middle-aged people had more esophageal strictures even in the presence of symptoms of dysphagia for a relatively shorter duration of time. 
The second most common finding on endoscopy was of achalasia cardia. It was commonly seen in patients who had a short duration of symptoms (<24 weeks), i.e. in 19 (13.9\%). Only one (0.7\%) patient with a duration of symptoms of $>24$ weeks had achalasia cardia. Both males and females had similar findings of achalasia cardia, i.e. 10 (7.3\%) each. It was more prevalent in the old age group of $>60$ years age in a frequency of 10 (7.6\%), whereas young and middle-aged patients had similar rates of achalasia cardia, i.e. in 5 (3.6\%) each. In one study, achalasia cardia was found to be the 4 th most common cause of dysphagia and was seen in $9.4 \%$ patients, and the majority of the patients were of age $<30$ years, i.e. $43.8 \%, 11.1 \%$ were of age 30-50 years and no patient above 50 years had achalasia cardia [5]. It was seen to affect males more and was frequently encountered in patients with short duration of symptoms. In another study, similar results were found in terms of gender and time of symptoms, but it was found to occur more frequently in old age patients who were $>50$ years [6]. The current study revealed similar findings in terms of duration of symptoms, and the higher prevalence of achalasia cardia in old age was similar to the results of the study reported by Khan et al. [6].

Thirdly, esophageal mass was found as a common finding. It was more common in old age people (61-80 years), i.e. in seven (5.1\%) patients followed by in middle-aged patients $5(3.6 \%)$ patients. It was more commonly seen in females seven (5.1\%) and was more frequent in patients with dysphagia of short duration, i.e. 9 (6.6\%). Yahya et al. reported that in patients with dysphagia, esophageal mass was a common cause, and it was reported to occur in $28.4 \%$ patients [7]. In our study, esophageal mass was found in $8.8 \%$ of patients. Findings similar to our study in terms of esophageal mass were reported by Gouda et al. as well [3].

A fourth common finding was that of reflux esophagitis in 7 (5.1\%) patients. Reflux esophagitis was slightly more frequent in females than males, i.e. four (2.9\%) and three (2.2\%) respectively. It was more frequent in patients with a short duration of symptoms, i.e. in $7.1 \%$ and was more frequent in middle-aged people, i.e. in 4 (2.9\%). Findings from other studies revealed similar prevalence rates in terms of gender. However, other studies showed that reflux esophagitis was more common in old age patients with duration of dysphagia for $>24$ weeks $[3-5,17]$.

This study had certain limitations. First of all, the study was carried out in a single-centre, so the results cannot be generalized to the general population with different dietary habits. Secondly, the sample size was small, so it cannot be taken as a representation of the whole population. Thirdly, endoscopy was only used for diagnosis, and the therapeutic use of the endoscopy was not evaluated. Lastly, the database did not provide thorough details for evaluation of causes of these findings and additional testing for further diagnostic confirmation was not done. Future studies on large sample size with subjects from various backgrounds and different dietary habits must be carried out in order to look for the association between demographics and findings on endoscopy as well as with other factors that can play an essential role in the pathogenesis of dysphagia.

\section{Conclusions}

Based on results, the current study concluded that the most common findings on endoscopy in patients with dysphagia were esophageal stricture, achalasia cardia, esophageal mass and reflux esophagitis. No significant association was found between the endoscopic findings and age, gender and duration of dysphagia. Upper gastrointestinal endoscopy must be carried out in all patients who present with dysphagia in order to look for causes like esophageal stricture, achalasia cardia, esophageal mass and reflux esophagitis, which if diagnosed earlier and treated promptly can reduce the risk of further morbidity and mortality associated with dysphagia. Endoscopy of the upper gastrointestinal tract is a safe, convenient and effective procedure for establishing the diagnosis and providing information about different treatment strategy.

\section{Additional Information \\ Disclosures}

Human subjects: Consent was obtained by all participants in this study. Ethical Committee of Pak Emirates Military Hospital Rawalpindi, Pakistan issued approval A/28-Sep-2019. The study was approved by the Ethical Committee of Pak Emirates Military Hospital Rawalpindi, Pakistan under appoval No. A/28-Sep2019. Animal subjects: All authors have confirmed that this study did not involve animal subjects or tissue. Conflicts of interest: In compliance with the ICMJE uniform disclosure form, all authors declare the following: Payment/services info: All authors have declared that no financial support was received from any organization for the submitted work. Financial relationships: All authors have declared that they have no financial relationships at present or within the previous three years with any organizations that might have an interest in the submitted work. Other relationships: All authors have declared that there are no other relationships or activities that could appear to have influenced the submitted work.

\section{References}

1. Cook IJ: Diagnostic evaluation of dysphagia. Nat Rev Gastroenterol Hepatol. 2008, 5:393-403. 10.1038/ncpgasthep1153

2. Krishnamurthy C, Hilden K, Peterson KA, Mattek N, Adler DG, Fang JC: Endoscopic findings in patients 
presenting with dysphagia: analysis of a national endoscopy database. Dysphagia. 2012, 27:101-5. 10.1007/s00455-011-9346-0

3. Gouda MS, Al-lakani AI, Bedewy MM: Endoscopic findings in Egyptian patients with oesophageal dysphagia at different age groups. Am J Internal Med. 2015, 3:224-30. 10.11648/j.ajim.20150306.12

4. Gilani N, Stipho S, Shaukat MS, Akins R, Ramirez FC: The yield and safety of string capsule endoscopy in patients with dysphagia. Gastrointest Endosc. 2007, 66:1091-5. 10.1016/j.gie.2007.04.034

5. Eslick GD, Talley NJ: Dysphagia: epidemiology, risk factors and impact on quality of life-a population-based study. Aliment Pharmacol Ther. 2008, 27:971-9. 10.1111/j.1365-2036.2008.03664.x

6. Khan AN, Said K, Ahmad M, Ali K, Hidayat R, Latif H: Endoscopic findings in patients presenting with oesophageal dysphagia. J Ayub Med Coll Abbottabad. 2014, 26:216-20.

7. Yahya M, Faruqi SJ, Memon AR: Endoscopic findings in patients presenting with dysphagia: an observational study. Int J Surg Med. 2020, 6:6-10. 10.5455/ijsm.Endoscopic-findings-patients-presentingdysphagia

8. Murata K, Ishikawa S, Sugioka T: Investigation of dysphagia symptoms and their association with subjective symptoms in inhabitants of an island. Gen Med. 2013, 14:32-9. 10.14442/general.14.32

9. Gupta A, Dall TS, Bansal D: Endoscopic evaluation of dysphagia. Int Surg J. 2019, 6:4323-6. 10.18203/23492902.isj20195387

10. Zameerulla T, Vivekanand D, Hanumathappa BN: Upper gastrointestinal endoscopy in patients with dysphagia: our experience. Int Surg J. 2019, 6:3960-2. 10.18203/2349-2902.isj20195104

11. Sachdeva K, Kaul V: Correlation of radiological and endoscopic findings in patients presenting with dysphagia. Indian J Otolaryngol Head Neck Surg. 2017, 69:72-6. 10.1007/s12070-016-1047-4

12. Solaro C, Cuccaro A, Gamberini G, et al.: Prevalence of dysphagia in a consecutive cohort of subjects with MS using fibre-optic endoscopy. Neurol Sci. 2020, 41:1075-79. 10.1007/s10072-019-04198-3

13. Panigrahi S, Khatua CR, Mishra D, Parida PK, Singh SP: A prospective study evaluating the etiologic spectrum in patients with dysphagia in coastal Odisha using clinical features and endoscopy. J Digest Endosc. 2019, 10:107-11. 10.1055/s-0039-1693286

14. Benjapornlert P, Kagaya H, Shibata S, Matsuo K, Inamoto Y, Kittipanya-ngam P, Saitoh E: The prevalence and findings of Fiberoptic Endoscopic Evaluation of Swallowing (FEES) in hospitalized patients with dysphagia. J Oral Rehabil. 2020, 47:983-88. 10.1111/joor.13026

15. Kamal A, Shakya S, Lopez R, Thota PN: Gender, medication use and other factors associated with esophageal motility disorders in non-obstructive dysphagia. Gastroenterol Rep. 2018, 6:177-83. 10.1093/gastro/goy018

16. Tye CB, Gardner PA, Dion GR, Simpson CB, Dominguez LM: Impact of fiberoptic endoscopic evaluation of swallowing outcomes and dysphagia management in neurodegenerative diseases. Laryngoscope. 2020, 00:15. 10.1002/lary.28791

17. Kim JP, Kahrilas PJ: How I approach dysphagia. Curr Gastroenterol Rep. 2019, 21:49. 10.1007/s11894-0190718-1

18. Simon SR, Florie M, Pilz W, et al.: Association between pharyngeal pooling and aspiration using fiberoptic endoscopic evaluation of swallowing in head and neck cancer patients with dysphagia. Dysphagia. 2020, 35:42-51. 10.1007/s00455-019-09992-x

19. Rückert J, Lenz P, Heinzow H, et al.: Functional endoscopy in neurogenic dysphagia . Endoscopy. 2018, 50:S48. 10.1055/s-0038-1637170

20. Prasad GA, Talley NJ, Romero Y, Arora AS, Kryzer LA, Smyrk TC, Alexander JA: Prevalence and predictive factors of eosinophilic esophagitis in patients presenting with dysphagia: a prospective study. Am J Gastroenterol. 2007, 102:2627-32.

21. Langmore SE: History of fiberoptic endoscopic evaluation of swallowing for evaluation and management of pharyngeal dysphagia: changes over the years. Dysphagia. 2017, 32:27-38. 10.1007/s00455-016-9775-x 